\title{
As periferias do mundo. Pasolini e o Brasil ${ }^{1}$
}

\author{
Maria BetÂnia Amoroso \\ Universidade Estadual de Campinas
}

\begin{abstract}
RESUMO: COMEÇANDO COM UMA BREVE HISTÓRIA DA RECEPÇÃO DO TRABALHO DE PASOLINI NO BRASIL, ESTE ARTIGO PRETENDE CONFRONTAR DOIS DE SEUS POEMAS, AMBOS CENTRADOS EM RETRATOS DE JOVENS DE SUBÚRBIOS DE ROMA E DO RIO DE JANEIRO.
\end{abstract}

ABSTRACT: BEGINNING WITH A BRIEF HISTORY OF THE RECEPTION OF PASOLINI'S WORKS IN BRAZIL, THIS ARTICLE INTENDS TO JOIN TWO POEMS BY THE POET, BOTH CENTERED IN THE PORTRAIT OF BOYS FROM ROME AND RIO DE JANEIRO SUBURBS.

PALAVRAS-CHAVE: PIER POALO PASOLINI - RECEPÇÃO NO BRASIL - GLAUBER ROCHA - POETA - CINEMA - REPRESENTAÇÃO DO POETA

KEY-WORDS: PIER PAOLO PASOLINI - BRAZILIAN RECEPTION - GLAUBER ROCHA - POETRY - CINEMA - REPRESENTATION OF THE POET

\footnotetext{
1 "Pasolini e o Brasil: das periferias ao periférico", apresentado no Convegno Internazionale PostScripta. Incontri possibili e imposibili tra culture (Università degli Studi di Bologna, Facoltà di Lingue e Letterature Straniere, 13 a 15/11/2003) e publicado no volume Post-Scripta. Incontri possibili e impossibili tra culture (a cura di Silvia Albertazzi, Gabriella Imposti e Donatella Possamai. Padova: Il Poligrafo, 2005, p. 81-92), foi o ponto de partida para este texto.
} 
primeira tradução no Brasil de um livro de Pasolini (1922-1975) foi feita somente em 1968. A obra escolhida foi o romance A bora depois do sonho (Il sogno di una cosa, 1962). O livro traduzido faz parte de uma coleção da extinta Edições Bloch de roteiros cinematográficos, embora essa narrativa não nasça nem se torne, em momento algum da sua trajetória, um roteiro. Serão os textos que acompanham a edição dos livros a fornecer aqui algumas pistas sobre a compreensão do momento da figura de Pasolini. A quarta capa, anônima, espécie de voz do editor, às voltas com o lançamento do livro-mercadoria, procura aproximar o leitor a uma determinada compreensão de Pasolini:

A hora depois do sonho é a incursão de um cineasta famoso no terreno do romance. Após a leitura, não se sabe em que plano ele aparece melhor, ficando desde logo fora de dúvida que em ambos é bom, excelente. Quem viu um filme como O Evangelho Segundo São Mateus terá a maior satisfação em conhecer uma obra como esta de Pier Paolo Pasolini na qual todos os ingredientes da ficção de qualidade funcionam. Seus protagonistas são jovens camponeses, simples e emocionais como a maioria dos comunistas italianos do campo, segundo a crítica. Vivem as agruras do desemprego, as desilusões de emigrados, o sonho (frustrado) de uma vida melhor, em que pudessem trabalhar e cantar. Em suma, aqui se estuda o ideal de corações simples em busca de uma felicidade que, a cada passo, parece mais distante, num horizonte indefinido. $\mathrm{O}$ ambiente da vida campestre e aldeã da Itália é descrito ao vivo, com a arte de um poeta. A tradução mantém, tanto quanto possível, o sabor típico do linguajar italiano que Pasolini prefere às vezes conservar em sua forma dialetal. Um romance que ninguém há de esquecer tão cedo.

É provável que se deva a $O$ Evangelho segundo São Mateus, filme premiado em 1964, na XXV Mostra de Cinema de Veneza, e visto por aqui, o impulso para a publicação do romance. Embora o romancista Pasolini que irá ter incidência sobre a história da narrativa italiana esteja muito mais representado nos livros escritos nos anos 1950 - Ragazzi di vita ${ }^{2}$ e Una vita violenta -, o que é

2 Trad. bras. Meninos de rua. São Paulo: Brasiliense, 1985. Texto extremamente difícil de ser traduzido, perde, na versão em português, a agressividade do dialeto e da fala dos moradores da periferia romana, o que já é, em si, uma interpretação. 
importante destacar são as formas e os sentidos que a aproximação a Pasolini foi assumindo no Brasil.

Nesse primeiro momento, a anacronia terá seu peso: A hora depois do sonho, escrito dentro do período de 1949 e 1952 e publicado pelo autor somente em 1962, traz ainda as marcas de uma poética liricizante, muito distante dos novos interesses que tão bem se mostram nos acontecimentos em torno dos episódios de 1968 na Itália - em 1969 totalmente desconsiderados nas traduções brasileiras -, em particular na ocupação da Universidade de Roma pelos estudantes e, em seguida, pelos policiais; os primeiros são duramente criticados pelo cineasta, quando Pasolini, em um poema, descreve a cena como a luta entre pais e filhos, declarando-se francamente favorável aos filhos de operários, os soldados, e em franca discordância com os filhos da burguesia. Seu famoso poema ${ }^{3}$ se inicia assim:

Sinto muito. A polêmica contra

o PCI tinha que ser feita na primeira metade

da década passada. Vocês, meus filhos, estão atrasados.

E não importa que vocês não tivessem ainda nascido...

Agora os jornalistas do mundo inteiro (inclusive

os da televisão)

ficam puxando (como acho que ainda se diz na linguagem

das universidades) o saco de vocês. Eu não, meus amigos.

Vocês têm cara de filhos de papai.

Odeio vocês como odeio seus pais.

Filho de peixe peixinho é.

Vocês têm o mesmo olhar maligno.

São medrosos, inseguros, desesperados

(ótimo!) mas também sabem como ser

prepotentes, chantagistas, convencidos, descarados:

prerrogativas pequeno-burguesas, meus amigos.

Ontem no Valle Giulia quando vocês brigavam

3 "O PCI aos Jovens (notas em verso para uma poesia em prosa)". O poema em prosa foi publicado pela primeira vez, como um "furo de reportagem", em L'Espresso, no dia 16 de junho de 1968; em seguida em Nuovi Argomenti, n. 10, abr.jun. 1968. Foi incluído no livro de Pasolini Empirismo eretico (1972). 
com os policiais, eu simpatizava com os policiais!

Porque os policiais são filhos de gente pobre.

Vêm das periferias, rurais ou urbanas que sejam.

Quanto a mim, conheço muito bem

seu jeito de terem sido crianças e rapazes, as preciosas mil liras, o pai que também continuou sendo um rapaz, por causa da miséria, que não confere autoridade.

A mãe calejada como um carregador, ou delicada, devido a alguma doença, como um passarinho;

os irmãos todos; o casebre

entre as hortas com a salva vermelha (em terrenos

alheios, loteados); o piso

sobre as cloacas; ou os apartamentos nas grandes

moradias populares.

$[\ldots]$

(PASOLINI apud LAHUD, 1993: 97)

Com o poema instaura-se, de imediato, uma polêmica de não pequenas proporções com todos aqueles que escolhem, nos episódios de 1968 das grandes capitais do Ocidente, celebrar a figura do "jovem" e do "universitário" como forças progressivas: autodeclarando-se "força do passado", tanto reconhece os traços de classe perdurantes como os fantasmas de ruínas que se anunciam pela idéia de progresso como fim inexorável de toda uma sociedade. Nesse poema em prosa, portanto, o poeta corsário já caminha na direção de sua crítica violenta contra padronização, contra o neo-fascismo, termos que sintetizam sua compreensão e análise de uma nova ordem econômica que vai se instalando e aniquilando qualquer vestígio do que a ela não se ajusta.

Em 1969, nova tradução: Teorema. Editada pela Nova Fronteira, acrescentamse, na orelha do livro, instruções sobre Como ler acertadamente este livro. São retiradas do próprio texto palavras do autor que tentam dirigir a atenção do leitor:

4 A expressão é parte de um dos versos mais conhecidos do autor italiano (Poesia in forma di prosa. Milano: Garzanti, 1964, p. 22). Pasolini utiliza-o também no episódio "A Ricota" (La Ricota), do filme Relações Humanas (Rogopag 1962-1963), declamado pelo personagem - um diretor de cinema - vivido por Orson Welles. 
Os primeiros dados desta nossa história consistem, muito modestamente, na descrição de uma vida familiar [...]. Acreditamos que não será sequer difícil (permitindo-nos portanto evitar certos detalhes de costumes já conhecidos) [...] imaginar uma a uma essas pessoas [...]. Como o leitor certamente já percebeu, o nosso, mais do que um conto, é aquilo que nas ciências se chama referto; ele é, portanto, muito informativo: por isso, tecnicamente, seu aspecto, mais do que o da mensagem é o do código [...]. Como é feio e inútil o significado da parábola, sem a parábola.

Ainda é realçado o hibridismo da forma:

Teorema nasceu, como sobre um fundo de ouro, pintado com a mão direita, enquanto com a esquerda eu afrescava uma grande parede (o filme homônimo). Em tal natureza anfibológica não sei sinceramente dizer qual prevalece: se a literatura ou a fílmica. Na verdade, Teorema tinha nascido como pièce em versos, há cerca de três anos; depois transformou-se em filme, e, contemporaneamente, no conto do qual o filme foi extraído e que pelo filme foi corrigido.

As palavras que soam mais fortes, entretanto, são as finais, nas quais Pasolini descreve para o leitor, na forma de frustração, seu empenho ideológico:

Quanto ao resto, o "livre discurso indireto" burguês, que querendo ou não, tive que tecer sob a urdidura da prosa poetizante, acabou contaminando a mim mesmo, até me dotar de um leve senso de humor, da distância, da medida (e tornando-me talvez, para minha grande raiva, menos escandaloso do que o tema teria exigido): tudo entretanto, creio, fica substancialmente observado e descrito de um ângulo visual extremista, talvez um pouco doce (eu o percebo), mas, em compensação, sem alternativas.

Uma orelha, portanto, substancial. A complexidade do autor e da figura consegue se deixar ver nas entrelinhas: desde os projetos de experimentação com a forma até a agressiva crítica ideológica tão desejada e nem sempre alcançada (também ela um problema da forma).

O mesmo livro será relançado em 1984 pela editora Brasiliense. São refeitos, então, tanto o texto de apresentação como a capa. Há uma nova versão de Pasolini insinuada nestas palavras: 
Esta não é uma história realista, mas uma parábola alegórica e enigmática. Nela, as cenas se encadeiam numa seqüência cinematográfica, compondo de forma extraordinária o cotidiano e a transformação das relações dentro de uma família pequeno-burguesa. Existe a princípio uma idéia no ar, um clima de estabilidade que logo será quebrado com a chegada de um visitante jovem, belo e atraente. As insatisfações, angústias e sentimentos dos seis membros da casa são desvelados à medida que o jovem vai se relacionando com cada um deles. E, gradualmente, a descoberta e a revelação de desejos sufocados revolucionam a vida familiar. Se causa surpresa o destino que tomam as coisas a partir de um certo ponto da narrativa, isso é porque este livro desnuda as raízes profundas do caos psicológico em que vivem os personagens e revela as regras selvagens de relacionamento que aí se estabelecem: raízes e regras do Teorema de Pasolini.

Na capa, o desenho de um dorso masculino, sobre o qual é projetado, em linhas pontilhadas, um triângulo cujo vértice aponta para baixo; na apresentação, realça-se subliminarmente não a complexidade intelectual da figura de Pasolini, mas sua psicologia, o que vai entendido como homossexualidade. As diferenças entre as duas publicações brasileiras do mesmo Teorema, no espaço de tempo de quinze anos, são extremamente significativas. Se na primeira é a idéia do estudo da sexualidade marcada pelos traços de classe a predominar, na segunda estamos nas searas da sexualidade enquanto manifestação da diferença. Lidas na contraluz, as informações editoriais de praxe indicam as novas interpretações de Pasolini que predominam: é um romance, dirá a página de rosto da nova editora, um relatório (não mais um referto na nova proposta da Brasiliense), reproduzindo parte do que o próprio autor disse sobre sua obra. $\mathrm{O}$ uso do termo relatório sugere o universo das pesquisas sobre a vida sexual tornadas conhecidas nos anos 1960, principalmente nos Estados Unidos, como o famoso Relatório Kinsey, e se amolda perfeitamente ao horizonte de interesses culturais da editora paulista naquele momento.

O que parece escapar à atenção editorial é a particularidade de Pasolini nesse debate: seu relatório-romance não cede ao viés único da observação objetiva e científica; sua observação do 68 italiano não o convida a celebrações de ordem política ou comportamental, porque nada de tão vital se alterou. Parte da constatação de ainda se tratar de uma sociedade rigidamente determinada em seus sentimentos de classe e da paralisia afetiva e ideológica que essa rigidez 
produz. O anjo exterminador, um jovem que se introduz na família, só realça, com sua extrema inocência e liberdade, o caráter ideológico, mais uma vez, de classe, da sexualidade italiana. ${ }^{5}$

Ainda em 1984, é lançada a tradução de Amado meu, pela mesma editora Brasiliense. Tendo na capa o título, à página de rosto acrescenta-se outro - Atos impuros, tendo a editora convidado um jovem escritor homossexual, Caio Fernando Abreu, para escrever uma nova apresentação do autor e do livro. Diz ele:

Lendo essas histórias - romances curtos, novelas, confissões de amor muito pessoal: que importa o nome - ficaram muitas coisas na minha cabeça. Antes de mais nada, a culpa que atormentava Pasolini por esse amor que chamam de homossexual. E o seu impulso em direção ao prazer de repente e sempre cortado pelo proibido de fora ou de dentro de nós. Fico pensando que, se existe alguma forma de modificar o mundo e as organizações sociais repressoras dentro dele, uma das mais eficientes talvez seja a dos poetas. Quando abrem o coração para, devagar e sofregamente, mostrar aos outros tudo o que se passa dentro dele. É nesse momento que conceitos como moral, certo, errado, bem ou mal deixam de ter sentido. Fica, no final de tudo, só a vida que flui e reflui sem nome, imensa.

Estão assim já traçadas algumas linhas de interpretação de Pasolini no Brasil. Ao lado do poeta lírico, preso ao mundo arcaico, acrescente-se a segunda pedra de toque, o escritor-poeta homossexual; no cruzamento das duas visões, o estereótipo do artista decadente.

Numa História da Literatura Italiana recente, essa percepção do artista decadente é vista como genericamente responsável pela ampla divulgação de Pasolini fora da Itália. No capítulo intitulado, aliás, "para além das fronteiras italianas”, os traços constitutivos dessa recepção são elencados:

5 Exemplar nesse sentido é o filme Comícios de amor (Comizi d'amore, 1963-1964). Nele Pasolini faz uma "enquete" junto a populares e intelectuais italianos sobre sexualidade. Como bem detectará Lahud, "[...] não se tratava [...] de realizar uma verdadeira enquête científica sobre os gostos sexuais dos italianos, e sim de compor [...] o mosaico dramático e revelador de uma condição cultural de vida" (LAHUD, 1993: 21). 
Muitos elementos contribuíram para tornar o nome de Pasolini um dos mais respeitáveis e conhecidos da segunda metade do século XX [...]. Acima de tudo, sua poliedricidade e versatilidade: Pasolini é romancista, poeta, dramaturgo, cineasta, ensaísta crítico e polemista. Deve-se a isso a diversificação de sua fama nos vários países nos quais se celebra um ou outro aspecto de sua obra. Mas o interesse propriamente literário, artístico ou pela linguagem expressiva de Pasolini foi despertado, adquirido ou mesmo sufocado pelo interesse pela sua vida, à qual, depois de tantas polêmicas, não faltou sequer o final trágico de uma morte violenta que teve enorme ressonância em todo o mundo. Desse ponto de vista, Pasolini (provavelmente ele seja o único) refaz, na recepção estrangeira, os rastros de D'Annunzio, que a seu tempo forjou sua notoriedade. Além disso, certa linha da tradição italiana o liga à imagem mítica de uma ruralidade sem tempo, à reavaliação do dialeto e das culturas orais; acrescente-se ainda as tomadas de posição políticas e ideológicas, e por fim, naturalmente, a homossexualidade. O bastante para transformá-lo em um autêntico personagem.

(D'INTINO apud CECCHI e SAPEGNO, 2001: 37-73)

A armadilha está criada: a atuação em tão diferentes áreas é compreendida como traço narcísico e não como característica de uma época e de um grupo intelectual de um tempo - a Itália do pós-guerra até aproximadamente os anos 1960 - anterior à especialização acadêmica do saber e da sua retração para dentro dos muros universitários. Por outro lado, é a figura do personagem público - e artista - da sociedade de massa e do espetáculo a predominar: tanto a homossexualidade como a predileção por traços descritivos advindos da psicologia comportamental sintetizam uma interpretação de Pasolini marcada tanto ideologicamente como por um certo existencialismo.

Sem dúvida alguma Pier Paolo Pasolini surgiu, nos anos 1960, no Brasil, como diretor de cinema. Aliás, em boa parte do mundo Pasolini se torna conhecido através de seus filmes, e, entre um público mais especializado, pela sua teorização sobre o cinema de poesia, que expôs em 1965, na Primeira Mostra Internacional do Novo Cinema, realizada em Pesaro (Itália). Personagem importante, ou mesmo protagonista da história dos cinemas novos, o brasileiro Glauber Rocha (1940-1981) escreveu sobre o cineasta italiano, e seus artigos são parte dessa outra história, a que nos contará sobre os modos e os momentos nos quais fomos nos aproximando da obra pasoliniana ao longo dos 
anos. Glauber e Pasolini: cada um a seu modo, inconformados com a situação de habitantes da periferia na qual pelo nascimento e cultura se inseriam, deixam entrever, de forma mais ou menos direta, um longo diálogo, que está em ambas as filmografias mas também fortemente nos textos de Glauber.

As semelhanças vão por conta, como diz Filippo La Porta (2002) a respeito de Pasolini, da "imaginação moral incontida" e de "furores existenciais" que os tornam personalidades únicas em seus respectivos países, em eterna luta contra o amesquinhamento de suas sociedades. O que os reúne, entretanto, aos nossos olhos de comparatistas, é a existência das periferias do mundo: a italietta abominável para Pasolini que se moderniza canhestra, perversa e tardiamente e o país em via de desenvolvimento cristalizado nessa condição cruel de que quem chegará sempre atrasado.

Paulo César Sarraceni, amigo íntimo de Glauber e participante ativo do $\mathrm{C} i$ nema Novo brasileiro, em vários momentos da sua autobiografia (SARRACENI, 1993) faz acenos a Pasolini. Conheceu-o em Roma, quando freqüentou o Centro Sperimentale di Cinema, nos anos 1960. Impressionado pela força das discussões travadas entre intelectuais e cineastas, que se reuniam em lendários bares romanos, Sarraceni, tocado pela inteligência e eloqüência de Pasolini, e pelas suas idéias sobre o cinema, pensa em apresentá-lo ao público brasileiro. Projeta uma entrevista para ser vendida para Manchete ou Cruzeiro, revistas de enorme circulação no Brasil naquele período. Ao imaginar que uma revista brasileira de variedades iria se interessar em publicar sua entrevista, já que "além de famoso poeta e romancista, Pasolini ia fazer seu primeiro filme", Sarraceni nos indica a familiaridade existente no círculo dos cinemanovistas em relação ao intelectual italiano.

Ismail Xavier não só foi um dos primeiros a apontar, no Brasil, a originalidade das discussões que o diretor italiano vinha propondo sobre o realismo, como também vislumbrou o paralelo possível entre Pasolini e Glauber:

Há um paralelo Glauber-Pasolini que se mostra na discussão pública em torno da pessoa do cineasta, um no Brasil outro na Itália, e nos pontos comuns das obras: o estilo rústico de câmara e montagem, a atenção à consciência popular, o diálogo com o mito, a preocupação com o inconsciente na política. Não por acaso, Pasolini é tema de vários artigos de Glauber - de elogio ou de vigoroso ataque - e é o cineasta lembrado no "sermão do planalto" de $A$ Idade da Terra. 
Depois da morte de Pasolini, "marcar posição" em face dele é uma preocupação constante de Glauber.

(XAVIER, 2001: 155)

Para sintetizarmos o "vigoroso ataque", a imagem de Pasolini altissonantemente desenhada por Glauber", embora não seja a única, é a do "intelectual europeu decadente" que, como homossexual, explora os meninos das áreas pobres das cidades por onde passa, opinião essa que endossa e engrossa a figura apenas delineada ou mesmo destacada do fundo composto pelos textos editoriais de suas traduções.

$\mathrm{Na}$ bibliografia brasileira, será Michel Lahud a retirar o nome de Pasolini do espaço único que lhe é geralmente reservado pela crítica de cinema, pela história da literatura e pela crônica de costumes, ao apresentá-lo "como um episódio exemplar da história das idéias" na sua coletânea de artigos, já publicados na Itália, mas reunidos de forma especial na versão brasileira que recebeu o sugestivo título Os jovens infelizes, livro editado em 1990, pela editora Brasiliense.

Francisco Foot Hardman, ele também peça importante na bibliografia pasoliniana brasileira, ao resenhar o livro, desvenda seu título-tese.

Parte considerável dos 31 textos que formam Os jovens infelizes é composta por artigos do jornalismo de combate que Pasolini praticou durante anos, extremamente virulentos, em especial os escritos no período marcado entre os inícios de 1973 e sua morte, no final de 1975. Na Itália toda essa produção foi reunida em duas obras: os Scritti corsari (1975) e as Lettere luterane (1976). Na edição brasileira, a seleção dessas intervenções ideológicas foi agrupada em três grandes blocos temáticos: 1) o fascismo de consumo: uma mutação antropológica; 2) A falsa tolerância sexual do novo poder; 3) A destruição, a falsa desobediência, a morte. No encerramento desta última parte, aparece a impressionante entrevista de $1^{\circ}$ de novembro de 75 já referida no início ${ }^{7}$. O volume conta, ainda, com uma unidade de abertura, constituída pelo artigo-tese que serve de título

6 Cf. ROCHA, Glauber. O Século do Cinema (1963), p. 276-286.

7 O resenhista abre seu artigo citando a entrevista concedida por Pasolini para o jornalista Furio Colombo, na véspera de sua morte, no dia 2 de novembro, a qual, sob sugestão do próprio Pasolini, saiu com a manchete: "Estamos todos em perigo". 
ao livro, escrito em janeiro de 1975 e publicado postumamente também na Itália. E, finalmente, com um apêndice, enfeixado pelo belo poema-manifesto "A poesia da tradição", de 1971, em que dialogando com o humanismo perdido de Dante, o canto pasoliniano lamenta, mais uma vez, a sorte infeliz dos filhos dessa geração:

onde rodopiava uma idéia confusa, uma absoluta certeza, uma presunção de heróis destinados a não morrer-

ó meninos desaventurados, que vistes ao alcance das mãos uma vitória maravilhosa que não existia.

(HARDMAN, 1990: 6-7)

Há um novo Pasolini aqui, cuidadosamente buscado, distante do homem de espetáculo - que, sem dúvida, Pasolini era -, incluído entre os pensadores da atualidade italiana. De modo muito feliz, Michel Lahud, no artigo intitulado Pasolini e o Brasil, publicado originalmente em 1985 - dez anos, portanto, depois da morte do poeta -, traduz o poema Hierarquia, registro poético da passagem do escritor italiano pelo Brasil.

Em 1970, conta-nos Lahud, Pasolini, voltando do Festival de Mar del Plata, onde, acompanhado por Maria Callas, fora apresentar Medéia, passa pelo Rio de Janeiro. Da sua passagem deixou o registro, naquela mesma forma do poema em verso, de "um extenso testemunho ideológico" (LAHUD, 1993: 121), Hierarquia. Assim como em O PCI aos jovens!, comparáveis enquanto forma testemunhal e depoimento ideológico, nesse poema Pasolini faz suas anotações de viajante em contato com a outra periferia, tão próxima daquela deixada na Itália pela ação unívoca exercida pelo capitalismo avançado sobre as sociedades modernas. São ambos expressivas antecipações do mal-estar característico das sociedades pós-modernas, expresso nos seus matizes ideológicos e de classe.

Hierarquia

Se chego numa cidade além do oceano

Chego muitas vezes numa cidade nova, transportado pela dúvida.

Convertido de um dia pro outro em peregrino de uma fé na qual não creio; 
representante de uma mercadoria há muito depreciada, mas é grande, sempre, uma estranha esperança Desço do avião com o andar do culpado, o rabo entre as pernas, e uma necessidade eterna de mijar, que me faz caminhar um tanto vergado com um sorriso incerto Safar-se da alfândega e, muitas vezes, dos fotógrafos: administração de rotina que cada um trata como exceção. Depois o desconhecido. Quem passeia às quatro da tarde ao longo dos canteiros cheios de árvores e pelos bulevares de uma cidade desesperada onde europeus pobres vieram recriar um mundo à imagem e semelhança do deles, forçados pela pobreza a fazer de um exílio a vida? De olho no meu trabalho, nos meus deveres Depois, nas horas vagas, começa minha busca, como se também ela fosse uma culpa A hierarquia está porém bem clara na minha cabeça.

Não há Oceano que resista.

Dessa hierarquia os últimos são os velhos.

Sim, os velhos, a cuja categoria começo a pertencer (não falo do fotógrafo Saderman que com sua mulher amiga já da morte me acolhe sorrindo no pequeno estúdio de toda a sua vida) Sim, existem alguns velhos intelectuais que na Hierarquia se colocam à altura dos michês mais bonitos os primeiros a serem encontrados nos lugares que a gente logo descobre e que como Virgílios nos conduzem com popular delicadeza alguns velhos são dignos do Empíreo, são dignos de figurar junto ao primeiro garoto do povo que se dá por mil cruzeiros em Copacabana ambos são o meu guia que me segurando pela mão com delicadeza, a delicadeza do intelectual e a do operário (além do mais desempregado) 
a descoberta da invariabilidade da vida requer inteligência e amor Vista do hotel da rua Resende Rio a ascese precisa do sexo, do caralho aquela portinhola do hotel onde se paga o cubículo se olha o Rio por dentro, numa aparência da eternidade, a noite de chuva que não refresca, - e banha as ruas miseráveis e os escombros, e as últimas cornijas do liberty dos portugueses pobres milagre sublime!

E portanto Josué Carrea é o Primeiro na Hierarquia e com ele Harudo, que veio criança da Bahia, e Joaquim.

A Favela era como Cafarnaum sob o sol Percorrida pelos regos dos esgotos barraco sobre barraco vinte mil famílias (ele na praia me pedindo cigarro como um prostituto) Não sabíamos que pouco a pouco nos revelaríamos, prudentemente, uma palavra após a outra, dita quase distraidamente: sou comunista, e: sou subversivo; sou soldado numa divisão especialmente treinada para lutar contra os subversivos e torturá-los; mas eles não sabem; ninguém se dá conta de nada; só pensam em viver (me falando do subproletariado) A Favela, fatalmente, nos esperava eu, grande conhecedor, ele, guia seus pais nos acolheram, e o irmãozinho nu recém-saído de trás do oleado pois é, invariabilidade da vida, a mãe conversou comigo como Maria Limardi, me preparando a limonada sagrada do hóspede, a mãe de cabelos brancos mas ainda jovem de carne; envelhecida como envelhecem os pobres, embora moça; sua gentileza e a de seu companheiro, fraternal com o filho que por sua exclusiva vontade era agora como um mensageiro da Cidade Ah, subversivos, procuro o amor e encontro vocês. 
Procuro a perdição e encontro a sede de justiça.

Brasil, minha terra,

Terra dos meus verdadeiros amigos,

Que não se ocupam de nada

Ou se tornam subversivos e como santos ficam cegos.

No círculo mais baixo da Hierarquia de uma cidade

imagem do mundo que de velho se faz novo,

coloco os velhos, os velhos burgueses,

porque um velho proletário da cidade continua sempre moço

não tem nada a perder -

anda de calção e camiseta como o filho Joaquim.

Os velhos, a minha categoria,

queiram eles ou não -

Não se pode fugir ao destino de possuir o Poder, ele se coloca sozinho

lenta e fatalmente na mão dos velhos,

mesmo que tenham as mãos furadas

e sorriam humildemente como mártires sátiros -

Acuso os velhos de terem apesar de tudo vivido,

acuso os velhos de terem aceitado a vida

(e não podiam não aceitá-la, mas não existem vítimas inocentes)*

a vida se acumulando deu o que queria dar -

acuso os velhos de terem feito a vontade da vida.

Voltemos à Favela

onde as pessoas ou não pensam em nada

ou querem se tornar mensageiras da Cidade

ali onde os velhos são filo-americanos -

Dentre os jovens que jogam bola com bravura

em frente a cumeeiros encantados sobre o frio Oceano,

quem quer alguma coisa e sabe que quer, foi escolhido por acaso -

inexperientes em imperialismo clássico

em qualquer delicadeza para com o velho Império a ser desfrutado

os Americanos separam uns dos outros os irmãos supersticiosos

sempre aquecidos por seu sexo como bandidos por uma fogueira de sarças É assim por puro acaso que um brasileiro é fascista e um outro subversivo; aquele que arranca os olhos 
pode ser tomado por aquele a quem se arrancam os olhos.

Joaquim não poderia jamais se distinguir de um facínora.

Por que então não amá-lo se o fosse?

Também o facínora está no vértice da Hierarquia, com seus traços simples apenas esboçados

como seu olho simples

sem outra luz que não a da carne

Assim no cume da Hierarquia

encontro a ambigüidade, o nó inextricável.

Ó Brasil, minha desgraçada pátria, devotada sem escolha à felicidade

(de tudo o dinheiro e a carne são donos

enquanto tu és assim tão poético)

dentro de cada habitante teu, meu concidadão,

existe um anjo que não sabe nada,

sempre debruçado sobre seu sexo, e, velho ou jovem, se apressa

a pegar em armas e lutar,

indiferentemente, pelo fascismo ou pela liberdade -

Ó Brasil, minha terra natal, onde

as velhas lutas - bem ou mal, já vencidas -

para nós, velhos, voltam a fazer sentido -

respondendo à graça dos delinqüentes ou dos soldados

à graça brutal.

(PASOLINI apud LAHUD, 1993: 117-129)

(*) Sartre.

Com Hierarquia Pasolini se auto-apresenta finalmente ao Brasil. O caudaloso poema em prosa se oferece à leitura em confronto com aquele outro, escrito em 1968: nesse poema brasileiro em prosa o poeta completa o anterior, encontra na cidade dolorosamente maravilhosa aqueles filhos da periferia e os dispõe fraternalmente próximos dos soldados que estavam do lado de lá dos estudantes romanos e compõe para esses meninos de periferia uma tristíssima elegia de amor. Há nesse amor uma terrível tragédia perfeitamente expressa, cujos heróis são os pobres meninos que vivem suas vidas recitando as mesmas partes reservadas historicamente para eles. Nessa perpectiva 
pasoliniana, os meninos do Rio reencenam diante de seus olhos admirados e comovidos a cena que já conhece com dor e de cor.

Desde Baudelaire podemos ver os poetas decadentes como perspicazes e sensíveis analistas das ruínas que o progresso e o desenvolvimento tecnológico, bandeiras eternas de um não menos eterno capitalismo, trouxeram para nossas cidades - cada vez mais, grandes periferias do mundo.

\section{Referências Biliográficas}

D'INTINO, Franco. Il Novecento Italiano Oltrefrontiera. In: CECCHI, E.; SAPEGNO, N. (a cura di). Storia della Letteratura Italiana, aggiornamento 11/12 di Natalino Borsellino e Lucio Felici (a cura di). Milano: Garzanti, 2001.

HARDMAN, Francisco Foot. Estamos todos em perigo. Idéias/Livros, Jornal do Brasil, 1990.

LAHUD, Michel. A vida clara. Linguagens e realidade segundo Pasolini. São Paulo/ Campinas: Companhia das Letras/Ed. Unicamp, 1993.

LA PORTA, Filippo. Pasolini. Uno Gnostico Innamorato della Realtà. Firenze: Le Lettere, 2002.

PASOLINI, Pier Paolo. O PCI aos jovens (notas em verso para uma poesia em prosa). In: LAHUD, Michel. A vida clara. Linguagens e realidade segundo Pasolini. São Paulo/Campinas: Companhia das Letras/Ed. Unicamp, 1993. . Hierarquia. In: LAHUD, Michel. A vida clara. Linguagens e realidade segundo Pasolini. Campinas/São Paulo: Editora da Unicamp/Companhia das Letras, 1993. . Trasumanar e organizzar. Milão: Garzanti, 1971.

. Teorema. Trad. Fernando Travassos. Rio de Janeiro: Nova Fronteira, 1969.

ROCHA, Glauber. O Século do Cinema (1963). São Paulo: Cosac Naify, 2006.

XAVIER, Ismail. Glauber Rocha: o desejo da história (1987). In: O Cinema

Brasileiro Moderno. Rio de Janeiro: Paz e Terra, 2001. (n. 11). 